\title{
From stormy seas to the doldrums: The challenges of navigating towards an ecologically coherent marine protected area network through England's Marine Conservation Zone process
}

\author{
Louise M. Lieberknecht ${ }^{a, b, 1}$, Peter J. S. Jones ${ }^{a}$ \\ ${ }^{a}$ Department of Geography, University College London, Pearson Building, Gower Street, London \\ WC1E 6BT; ${ }^{b}$ Independent Consultant; ${ }^{1}$ Corresponding author: louisemarie.lieb@gmail.com
}

\begin{abstract}
There is an on-going process to establish Marine Conservation Zones (MCZs) in England, to form part of a coherent and representative network of marine protected areas under national and EU legislation. From 2009 to 2011, the MCZ process included strong participatory elements. Four regional multisector stakeholder groups developed MCZ recommendations collaboratively, in line with ecological guidance provided by the Government's nature conservation advisers. This guidance was based on Government policy principles, including that MCZs should be designated based on 'best available evidence'. This paper analyses the multi-dimensional conflicts that emerged within the stakeholder group in south-west England, which were magnified by uncertainty about future MCZ management. In September 2011, after working through these conflicts through trade-offs and negotiations, the stakeholder groups jointly recommended $127 \mathrm{MCZs}$ to Government. The process subsequently shifted to a top-down approach, with further stakeholder engagement limited to bilateral consultation. There was a concurrent shift in policy, from a broad-scale network-level focus towards single-feature conservation. A lengthy series of evidence reviews concluded that the existing evidence at the time was insufficient to progress with the designation of most sites, marking a clear departure from the policy principle of proceeding with the designation of a representative network based on 'best available evidence', and effectively undermining the work carried out by stakeholder groups. Though MCZ designation was originally timetabled for 2012, in November 2013 just 27 of the recommended $127 \mathrm{MCZs}$ were designated in a first tranche. At the time, no clear timetable was in place for subsequent tranches.
\end{abstract}

\section{Highlights}

- The realities of marine spatial planning contrast with related conceptual ideals.

- National blue growth priorities lead to a focus on 'strategic sectoral planning'.

- Top-down approaches dominate from which participative platforms are disconnected by design.

- Politically expedient focus on integrated-use is undermining environmental priorities.

- A more critical empirical approach to marine spatial planning research is needed.

\section{Keywords}

Marine Conservation Zones; Marine protected areas; Marine spatial planning; Stakeholder participation

This is the authors' version of the final accepted Marine Policy manuscript. Elsevier@ 2016. This manuscript version is made available under the CC-BY-NC-ND 4.0 license.

http://dx.doi.org/10.1016/j.marpol.2016.05.023

\section{@creative}

Lieberknecht LM and Jones PJS (2016) From stormy seas to the doldrums: The challenges of navigating towards an ecologically coherent MPA network through England's Marine Conservation Zone process. Marine Policy 71, 275-284. http://dx.doi.org/10.1016/j.marpol.2016.05.023 Elsevier@2016. This manuscript version is made available under the CC-BY-NC-ND 4.0 license 


\section{Introduction}

Background and focus of this paper

This paper analyses the on-going process to establish Marine Conservation Zones (MCZs) in England, under the Marine and Coastal Access Act 2009' (the Marine Act). The Marine Act places a duty on the Secretary of State for the Environment (the UK's environment minister) to designate MCZs in English watersii. The legislation requires MCZs to complement sites designated under pre-existing legislation, (e.g. marine Natura 2000 sites under the EU Habitatsiii and Birdsiv Directives), in order to form a network of marine protected areas (MPAs) that fully represents the range of marine features present in national waters ${ }^{v}$.

The EU Habitats and Birds Directives specify individual features (species and habitats) that qualify for protection - MCZs, on the other hand, can be designated for any marine feature ${ }^{\mathrm{vi}}$. The Marine Act thereby provides the legal underpinning for a network that is truly representative of the full range of flora and fauna on England's continental shelf, in compliance with article 13 (4) of the EU Marine Strategy Framework Directive (MSFD), which requires Member States to establish 'coherent and representative' MPA networks by $2016^{\text {vii. }}$

In 2010, Defra (the national environment ministry) made a wider policy commitment 'to develop an ecologically coherent and well-managed network of Marine Protected Areas (MPAs) that is well understood and supported by sea-users and other stakeholders' [1]. At the time, they defined 'ecological coherence' based on seven principles, first announced in a written Ministerial Statement on MCZs ${ }^{\text {viii, }}$ and subsequently written into ministry-level policy guidance [1]. The seven principles included representativity (in line with the requirements of the Marine Act and MSFD), and the principle that site selection would proceed based on the best available evidence (and not be delayed by gaps in scientific knowledge).

This paper focuses on the time period between 2009 and April 2013. For the first part of that time period (2009 to September 2011), four separate MCZ projects operated in four English regions. This paper focuses on Finding Sanctuary, the south-west regional project (although the basic similarities between the four projects, and their shared national context, mean that the findings are relevant to the English MCZ process as a whole). For the time period from late 2011 to April 2013, the paper focuses on the centrally-run national MCZ process, highlighting changes in the governance approach following the end of the regional projects, and the consequences of these changes.

\section{Sources and research methods}

University College London is an independent observer of the MCZ process, though the first author previously worked as Finding Sanctuary's MPA planner. Her first-hand experience of Finding Sanctuary is complemented by the second author's independent observations of 24 of the regional project's stakeholder meetings. In order to understand stakeholder perspectives on the process after their participation ended in 2011, semi-structured interviews were conducted with 23 former Finding Sanctuary stakeholder group members in June and July 2012 [2]. Interviewees spanned the spectrum of sectors and interest groups.

Lieberknecht LM and Jones PJS (2016) From stormy seas to the doldrums: The challenges of navigating towards an ecologically coherent MPA network through England's Marine Conservation Zone process. Marine Policy 71, 275-284. http://dx.doi.org/10.1016/j.marpol.2016.05.023 Elsevier@2016. This manuscript version is made available under the CC-BY-NC-ND 4.0 license 
In addition to the direct observations and interviews, a detailed document analysis was carried out. This covered Finding Sanctuary's 29 regional stakeholder meeting reports, 3 progress reports, and the final report [3], as well as grey literature relating to the national process - legislation and policy documents, advice from nature conservation bodies, official newsletters, news items, Government websites, and public consultation documents. These sources are fully catalogued in [2], whilst citations in this paper are limited to key documents. This research followed the governance analysis approach and structure developed as part of the MESMA project [4].

\section{Case study process and governance}

Figure 1 illustrates key institutions and their roles within England's MCZ process. Under the Marine Act, the UK's environment minister holds decision-making power over site designation, but must ensure that the requirements of section 123 of the Marine Act are met. The environment ministry (Defra) defines broad MCZ policy, and has overall responsibility for MCZ planning.

The ministry is supported by two statutory nature conservation bodies (SNCBs), Natural England and the Joint Nature Conservation Committee (JNCC), who provide marine conservation advice for the areas within and beyond territorial waters, respectively. The SNCBs hold no decision-making power, but have a statutory role to advise Defra on the appropriate number, location, and conservation objectives of MCZs, in line with legal and policy objectives.

Regulatory authorities (primarily, the Marine Management Organisation or $\mathrm{MMO}$, and the Inshore Fisheries and Conservation Authorities or IFCAs) have the legal responsibility to implement management measures within MCZs, e.g. byelaws to limit specific human activities, in order to ensure that MCZ conservation objectives are met. In the MCZ process, management measures are not determined prior to site designation. Instead, the regulatory authorities will take management decisions on a case-by-case basis, following the designation of the sites. The SNCBs have a role to advise regulatory authorities on anthropogenic impacts that may impede the achievement of conservation objectives, but have no power to define management measures.

One key exception is that in sites beyond 6 nautical miles, any restricitons on fishing activity have to be implemented through the EU Common Fisheries Policy, adding a significant degree of complication and uncertainty. In the EU, biodiversity conservation is the responsibility of individual member states, but fisheries management falls under the exclusive jurisdiction of the EU, causing tensions which were discussed in relation to Natura 2000 sites by [5].

The roles and responsibilities within the MCZ process essentially mirror England's marine Natura 2000 process. However, in the latter, the SNCBs develop site proposals through a fully top-down process, based solely on scientific criteria and scientific survey data. In the MCZ process, in contrast, initial site planning was carried out through a combination of top-down guidance and collaborative stakeholder work. The SNCBs established four regional projects, in which regional stakeholder groups (RSGs) were tasked with developing initial recommendations for MCZ locations, boundaries, and conservation objectives, in line with guidelines written by the SNCBs (see below). Defra was initially a member of the MCZ Project Board (the overarching body responsible for managing the MCZ process nationally

Lieberknecht LM and Jones PJS (2016) From stormy seas to the doldrums: The challenges of navigating towards an ecologically coherent MPA network through England's Marine Conservation Zone process. Marine Policy 71, 275-284. http://dx.doi.org/10.1016/j.marpol.2016.05.023 Elsevier@2016. This manuscript version is made available under the CC-BY-NC-ND 4.0 license 
whilst the four RSGs operated), but stepped back early on, effectively delegating all responsibility for the stakeholder process to the SNCBs.

RSG membership spanned the full spectrum of maritime interests. The task of the RSGs was guided by ecological network guidelines (ENG), authored by the SNCBs [6]. The ENG defined the detailed ecological criteria the MPA network needed to fulfil in order to qualify as 'ecologically coherent', based on the seven network principles in Defra's policy guidance [1]. A Science Advisory Panel (SAP), consisting of natural scientists, was established by Defra to provide scientific advice and guidance, as well as feedback on the developing network recommendations, using the ENG as a benchmark. The SAP's role was purely advisory, with no direct role in designing site recommendations ${ }^{\mathrm{ix}}$.

The RSGs worked through a collaborative process from 2009 until 2011, supported by four dedicated project teams, ultimately submitting recommendations for 127 sites in September 2011, with 58 of those sites recommended by Finding Sanctuary [3]. These recommendations were arrived at through an intensive process of negotiation and compromise. A final review by the SAP concluded that the recommendations would, if fully implemented, meet most of the ENG guidelines [7]. The regional projects ceased operating following the delivery of their recommendations.

The SNCBs spent a year carrying out a detailed review of the RSG recommendations, along with their underpinning scientific evidence, in a non-participative process that remained inaccessible to most stakeholders (see below). They published their formal advice on MCZs to Defra in July 2012, recommending, in essence, the designation of the sites put forward by the regional projects [8]. The original process timetable had scheduled designation of MCZs by 2012, but a second written Ministerial Statement on MCZs in November 2011 announced that this would be significantly delayed, and that designation would be phased, with a 'first tranche' of sites to be designated in the summer of $2013^{x}$ (this was subsequently delayed further until November 2013).

Following consideration of the formal SNCB advice, in December 2012 Defra announced that 31 of the 127 recommended sites were under consideration for possible designation in 2013, and opened up these proposals for comment in a public consultation. In March 2013, Defra published a document outlining the criteria they had used to select the 31 sites [9]. The criteria combined the potential socioeconomic cost of MCZs, the current risk of damage to sites (as assessed by the SNCBs in their advice to Defra), and the levels of scientific evidence underpinning each individual conservation objective in each site. Potential costs were quantified through a formal Impact Assessment (IA). Given the lack of decisions on how sites would be managed following designation, potential cost ranges were based on a range of 'illustrative' management scenarios [10]. Of the 31 sites, 27 were designated in November 2013.

\section{Process overview}

Figure 1 illustrates the key organisations involved in the MCZ process, and their formal roles, whilst figure 2 presents a simplified timeline of the process. Although decision-making power was retained by Government, the regional projects built strong participatory (bottom-up) elements into the MCZ process. These were combined with top-down elements, such as the ENG and Defra policy guidance. Following the end of the regional projects, the MCZ process shifted to a top-down approach, with the

Lieberknecht LM and Jones PJS (2016) From stormy seas to the doldrums: The challenges of navigating towards an ecologically coherent MPA network through England's Marine Conservation Zone process. Marine Policy 71, 275-284. http://dx.doi.org/10.1016/j.marpol.2016.05.023 Elsevier@2016. This manuscript version is made available under the CC-BY-NC-ND 4.0 license 
role of stakeholders limited to the opportunity to provide comments on the proposed first tranche of designations during a bilateral consultation period. Following the end of the regional projects, no further incentives for cross-sector communication, negotiation, or collaboration were designed into the process.

It is expected that Government will publish a response to the $2012 / 2013$ public consultation feedback when the first site designations are announced. At the time of writing, it is uncertain how many sites will be designated within the first tranche, or when a process or timeline for possible future tranches might be announced. Furthermore, there is no clear roadmap or timeline for the process through which responsible authorities will define MCZ management measures following designation. Thus, future progress towards an ecologically coherent, representative, and well-managed MPA network in English waters remains uncertain.

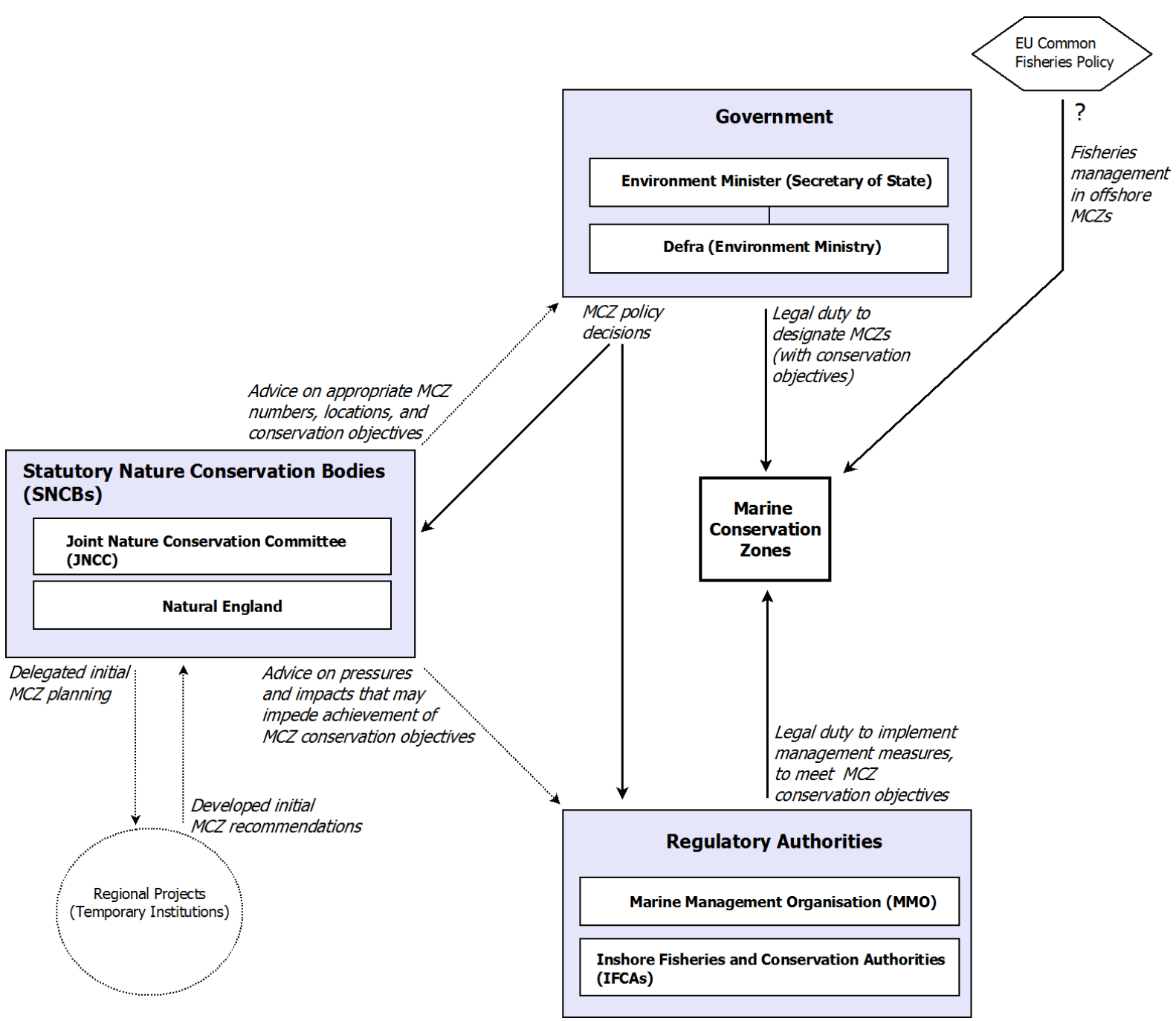

Figure 1. Simplified governance diagram indicating the formal roles played by key bodies within England's MCZ process.

Lieberknecht LM and Jones PJS (2016) From stormy seas to the doldrums: The challenges of navigating towards an ecologically coherent MPA network through England's Marine Conservation Zone process. Marine Policy 71, 275-284. http://dx.doi.org/10.1016/j.marpol.2016.05.023 Elsevier@2016. This manuscript version is made available under the CC-BY-NC-ND 4.0 license 


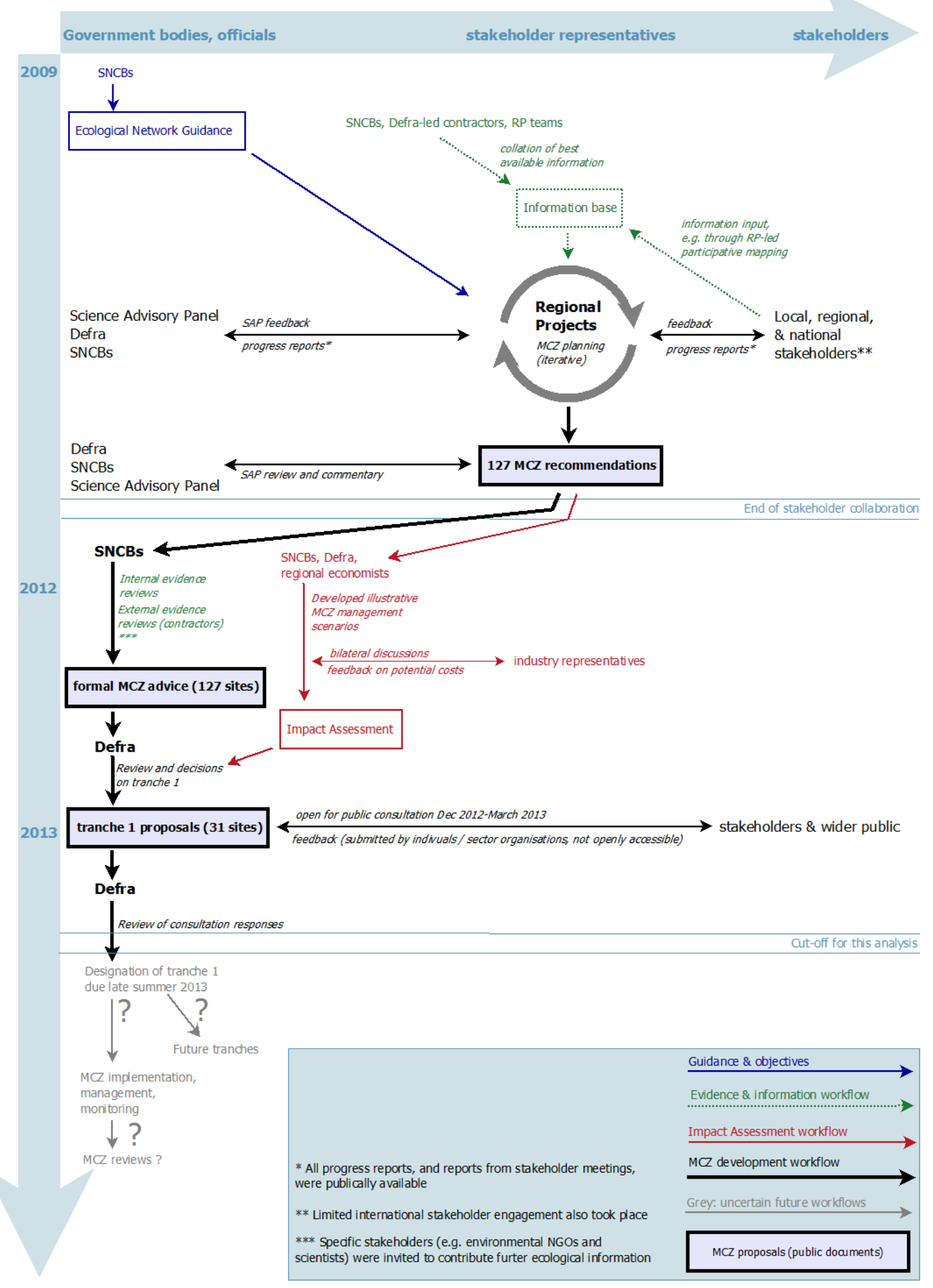

Figure 2 Simplified timeline illustrating key workflows in England's MCZ process up to the end of 2013. $\mathrm{SAP}=$ Science Advisory Panel, RP = Regional Project

Lieberknecht LM and Jones PJS (2016) From stormy seas to the doldrums: The challenges of navigating towards an ecologically coherent MPA network through England's Marine Conservation Zone process. Marine Policy 71, 275-284. http://dx.doi.org/10.1016/j.marpol.2016.05.023 Elsevier@2016. This manuscript version is made available under the CC-BY-NC-ND 4.0 license 


\section{Conflict analysis for the south-west regional project (Finding Sanctuary)}

All four RSGs worked through an intensive process of discussions and negotiations to develop their MCZ recommendations, during which significant conflicts emerged. The most significant conflicts emerging in Finding Sanctuary's RSG can be represented as a triangle between offshore renewable representatives, offshore fishermen, and conservationists proposing MCZs (figure 3). There was a shared assumption that safety measures would ban mobile gear fishing within wind farms, leading to a conflict between the interests of offshore mobile fleet representatives, and offshore renewables representatives. Most stakeholders assumed that offshore fishing using towed gears (especially demersal gears) would either be restricted or banned in MCZs, so there was a conflict between conservation and fisheries interests.

There was considerable debate within the RSG about the compatibility of renewable energy installations and MCZs. Several RSG members considered wind farms as 'de-facto MPAs', because of the safety restrictions on fishing activity that existing wind farms enforce. The SAP highlighted scientific evidence that offshore wind farms can have biodiversity benefits as well as negative impacts (e.g. [11]). However, given that the design of the MCZ process meant that MCZ management would uncertain until after site designation (with RSGs not empowered to address management), offshore renewables representatives generally opposed MCZs being located within areas of interest for renewables development. The uncertainty made them see MCZs as a risk, fearing possible restrictions on development or added operational costs to their sector.

The main driving force for this conflict triangle was competition for space. The three sectors involved all occupy very large spatial footprints, or are potentially set to do so in future. Fishing activity already occupies virtually the entire continental shelf off south-west England, a highly productive area, which is fished more intensively than other English waters, including by bottom towed gears [12]. RSG members recognised that MSFD and Marine Act require a significant increase in the spatial footprint of MPAs (not only MCZs: In 2010 and 2011, proposals for several large new south-west Natura 2000 sites were made public by the SNCBs, which had been developed in a separate, non-participative process). At the same time, obligations under the 2009 EU Renewable Energy Directive ${ }^{\mathrm{xi}}$ are driving interest in the development of offshore renewables. At the time of Finding Sanctuary's RSG meetings, two large offshore wind farms were planned in the region, the Atlantic Array in the Bristol Channel, and Navitus Bay off Dorset. There was an expectation that wave and tidal technology would also be developed in the region in future, with the WaveHub ${ }^{\text {xii }}$ providing infrastructure for testing wave energy devices.

The growth in offshore renewables had knock-on effects on the conflicts between fishermen and conservationists: Fishermen perceived MPAs and offshore renewables to be simultaneously encroaching on 'their' territory, linking and intensifying the conflicts. Because of the intensity and large spatial scale of this conflict triangle, trade-offs between the three sectors involved had a significant influence on the spatial configuration of Finding Sanctuary's recommended sites. The same 'race for space' was identified by Qiu and Jones [13] as an important driver of conflicts and tensions in wider marine spatial planning in European waters.

Lieberknecht LM and Jones PJS (2016) From stormy seas to the doldrums: The challenges of navigating towards an ecologically coherent MPA network through England's Marine Conservation Zone process. Marine Policy 71, 275-284. http://dx.doi.org/10.1016/j.marpol.2016.05.023 Elsevier@2016. This manuscript version is made available under the CC-BY-NC-ND 4.0 license 
RSG members recognised that the co-location of MCZs with wind farms would ease their combined impact on fishermen, but as highlighted above, uncertainty about MCZ management prevented offshore renewables representatives from agreeing to co-location. A notable exception was that the developer of the Atlantic Array agreed to their planned wind farm area being recommended as an MCZ, after detailed bilateral discussions with Natural England, and being satisfied that an MCZ designation would not have an unacceptable impact on the planned wind farm development. This was a 'win-win' in the eyes of the stakeholder group. However, Defra did not include the site in the 31 'tranche 1 ' sites. Local fishermen continue to be concerned about combined impacts of the Atlantic Array and future MCZs on their livelihoods [14].

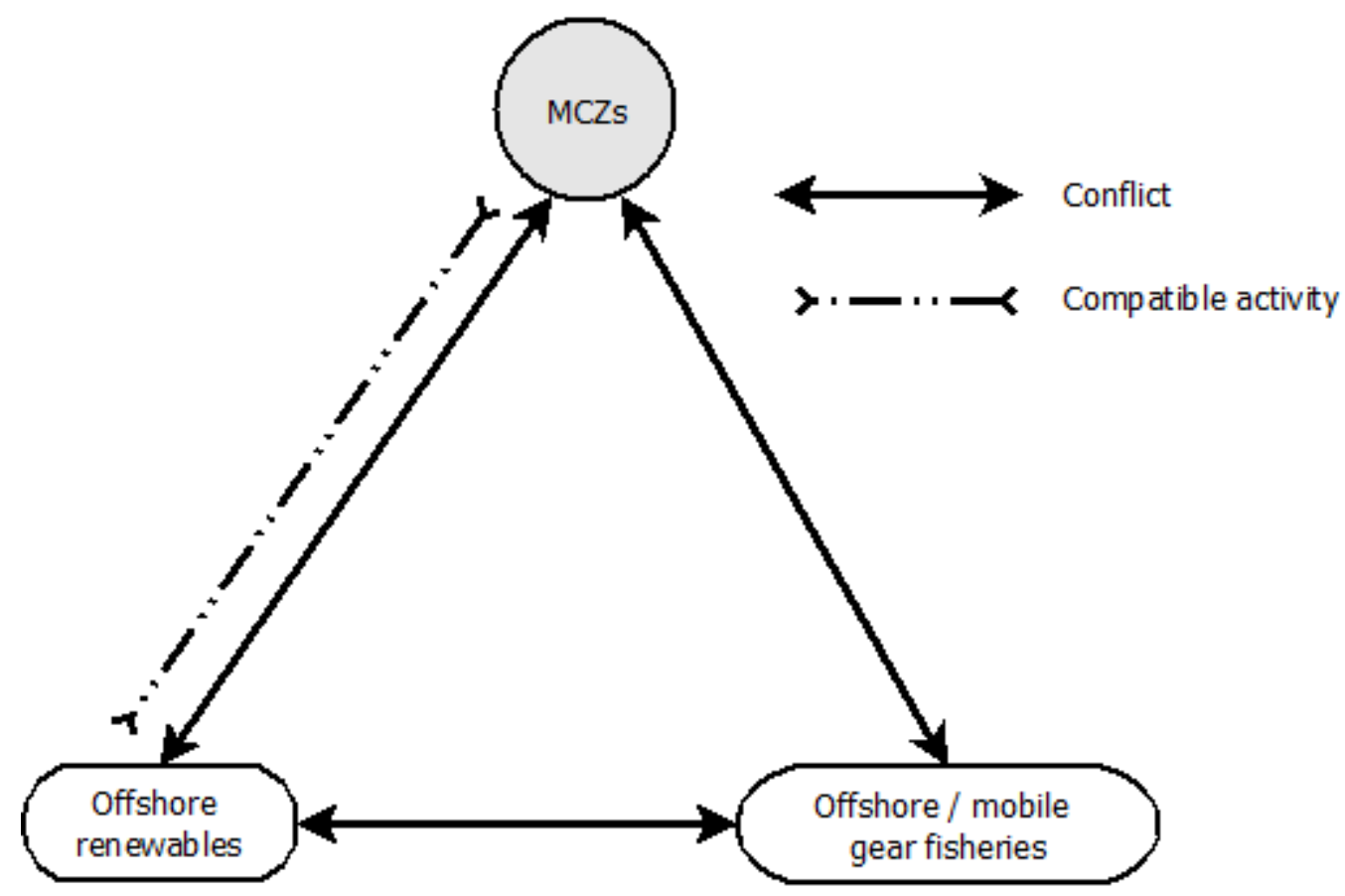

Figure 3 The key conflict triangle that emerged during Finding Sanctuary's RSG discussions. The link between offshore renewables and MCZs is shown as a conflict as well as a synergy, given that offshore wind farms can have positive as well as negative local impacts on biodiversity, and the possibility of co-locating wind farms and MCZs was explored during the planning discussions.

Lieberknecht LM and Jones PJS (2016) From stormy seas to the doldrums: The challenges of navigating towards an ecologically coherent MPA network through England's Marine Conservation Zone process. Marine Policy 71, 275-284. http://dx.doi.org/10.1016/j.marpol.2016.05.023 Elsevier@2016. This manuscript version is made available under the CC-BY-NC-ND 4.0 license 
Beyond the key conflict triangle illustrated in figure 3, many additional conflicts emerged during Finding Sanctuary's stakeholder discussions, which can be grouped into three categories:

1. Conflicts between conservation and human use, e.g. fishermen (including inshore and static gear fishermen), the ports sector, recreational boat users, offshore cables, and the aggregates industry.

2. Conflicts between different human activities, e.g. between busy shipping lanes and renewables installations (as well as the above mentioned between offshore renewables and offshore fishermen).

3. Conflicts within human use sectors, the most notable one being between fishermen (e.g. between static and mobile gear fishermen, and between small-vessel inshore fishermen and large-vessel offshore fishermen).

Whilst the main conflict triangle shaped the developing network configuration over broad spatial scales, other conflicts tended to emerge in relation to more spatially confined areas. They affected recommended site boundaries for individual sites through the exploration of local trade-offs, but had less impact on shaping the network at a regional scale than the triangle of key conflicts. Some of these more localised conflicts were nevertheless very intense. For example, there was strong opposition from port industry representatives to MCZs virtually anywhere near ports or harbours. Particular severe conflicts flared up in relation to a proposed site near Falmouth Harbour in Cornwall, where there were plans for expanding the port. At Studland Bay off Dorset, there was strong conflict between conservationists, who proposed an MCZ to protect local seagrass beds and seahorse populations, and recreational boat users: The site provides sheltered anchorage and is a popular day-trip destination from nearby urban areas.

Neither of these conflicts was caused solely by the MCZ process - i.e. the MCZ process lead to the manifestation of pre-existing latent conflicts. In Falmouth, there was already intense conflict between the local port authority and conservationists over fears that the port expansion would damage maërl beds protected in an existing Natura 2000 site, as documented on the MMO website ${ }^{\text {xiii }}$, and in local and national media reports ${ }^{\mathrm{xiv}}$. In Studland Bay, local conservationists had been demanding anchoring restrictions for several years, causing significant on-going conflict with recreational boaters, attracting national media coverage ${ }^{\mathrm{xv}}$. There was no conflict between Falmouth harbour officials and recreational boat users in Studland Bay, but because Finding Sanctuary operated at a regional scale, the discussions about these two alternative MCZ locations effectively meant that the RSG had to trade off their respective concerns against each other. This example illustrates the complex and unexpected interrelationships between the varied conflicts that emerged in this process, as well as the practical complications that arise from considering conflicts and impacts at different spatial scales.

When analysing the links between different conflicts surrounding the development of MCZ proposals, it is also important to consider synergies that were identified within the process, as some of them offered potential ways of reducing conflicts. For example, there was a general assumption that shipping traffic would not be restricted in MCZs. Several IMO Traffic Separation Schemes exist in south-west waters, which effectively hamper other activities within them (such as fishing), or prevent

Lieberknecht LM and Jones PJS (2016) From stormy seas to the doldrums: The challenges of navigating towards an ecologically coherent MPA network through England's Marine Conservation Zone process. Marine Policy 71, 275-284. http://dx.doi.org/10.1016/j.marpol.2016.05.023 Elsevier@2016. This manuscript version is made available under the CC-BY-NC-ND 4.0 license 
them entirely (such as wind farms). Locating MCZs within these shipping lanes was seen as a 'win-win' solution by many.

Another potential synergy was identified between MCZs and static gear fishing carried out by small inshore vessels, which most stakeholders saw as environmentally benign, and there was a widespread assumption that no restrictions would be imposed on this activity. Some static gear fishing representatives proposed their favoured fishing grounds as MCZs, based on the assumption that mobile gears would be banned - they saw MCZs as a vehicle for resolving pre-existing fishing gear conflicts in their favour (in what might be termed a 'win-lose-win' scenario). These proposals caused conflicts with mobile gear fishing representatives.

Figure 4 is a simplified graphic representation of the varied conflicts (and relevant synergies) that emerged within Finding Sanctuary's stakeholder discussions, and the multiple linkages between them. Essentially, this figure combines multiple 'conflict triangles' into a 'conflict wheel'. MCZs form the hub, the conflicts (and synergies) between MCZs and human activities form the spokes, and the interactions between different human activities the rim of the wheel.

Additional interactions exist between the actors around the rim, some of which are of great significance to the respective sectors and activities. For example, aggregate extraction and fishing with benthic mobile gear cannot take place where there are cables and pipelines, so there is the potential for conflicts over the location of cable routes, and all offshore activities are dependent on port infrastructure, so there are strong synergies between ports and other sectors. These additional interactions are not shown here, as they were of limited direct consequence within the specific context of shaping MCZ recommendations - they would, however, be of significance in integrated, multi-sector marine spatial planning, an approach that is advocated as a means of resolving conflicts between maritime users, and as a vehicle for improving marine environmental management [15-17].

Lieberknecht LM and Jones PJS (2016) From stormy seas to the doldrums: The challenges of navigating towards an ecologically coherent MPA network through England's Marine Conservation Zone process. Marine Policy 71, 275-284. http://dx.doi.org/10.1016/j.marpol.2016.05.023 Elsevier@2016. This manuscript version is made available under the CC-BY-NC-ND 4.0 license 


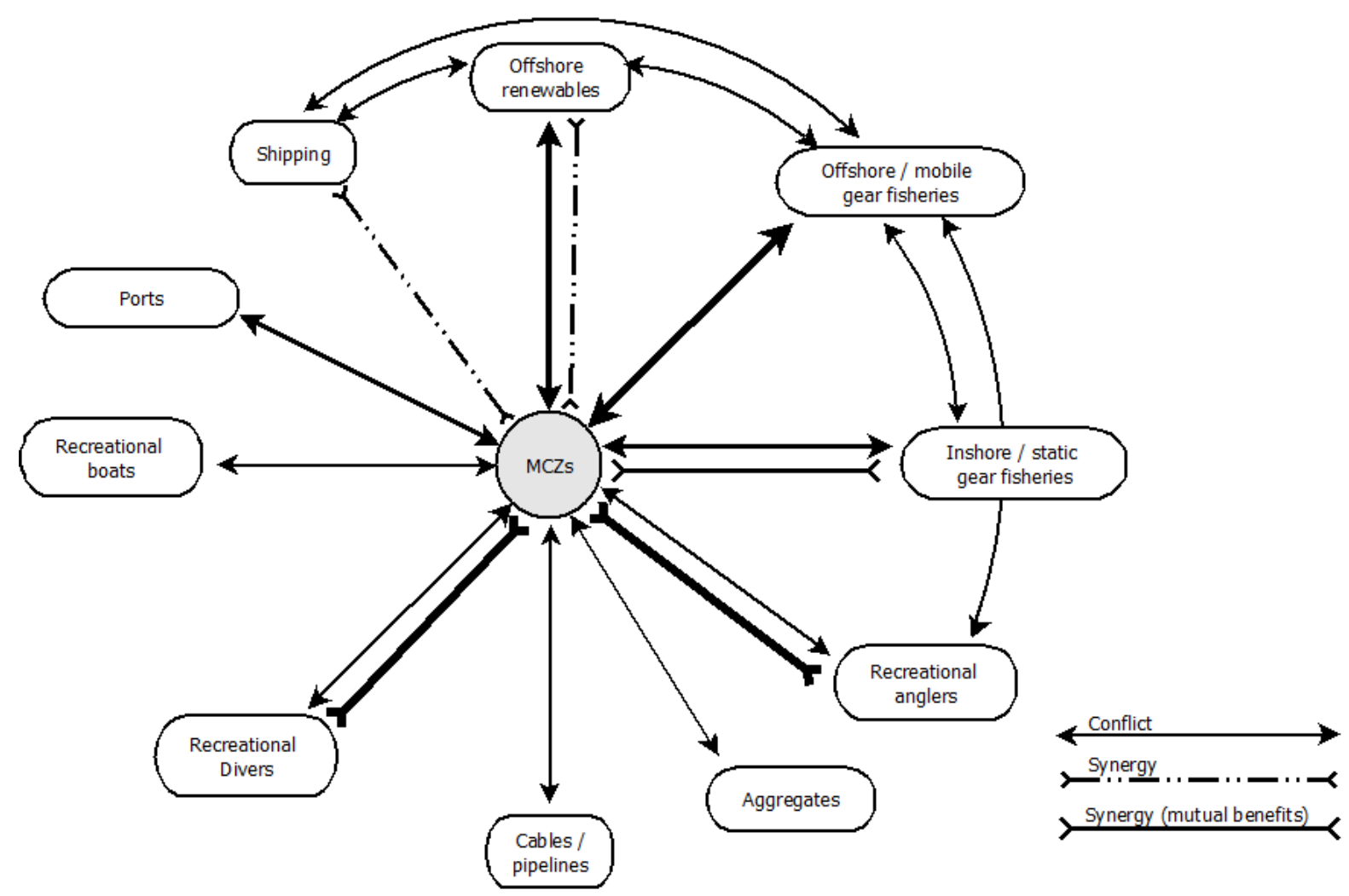

Figure 4 The wheel of conflicts and potential synergies that emerged during Finding Sanctuary's stakeholder process.

Uncertainty about future MCZ management was an important driver of conflicts within the context of Finding Sanctuary's RSG. Because no-one was sure about the consequences that MCZs would have for human activities, MCZ recommendations had to be based on assumptions. Industry representatives frequently assumed a 'worst-case scenario' for their sector (e.g. the offshore renewables representatives in the key conflict triangle discussed above), even where there was a strong possibility that future restrictions would be less severe. Thus, uncertainty potentially created needless conflicts (extra 'spokes' in the wheel), adding to the overall complexity of the linkages.

A lot of time and effort was spent attempting to formulate a set of shared assumptions for the group, but this proved virtually impossible - a mixture of fears, hopes, and expectations made it difficult even for individual stakeholders to articulate straightforward assumptions. Discussions got mired in conflicts over what restrictions should be implemented, which restrictions would (realistically) be likely, and which assumptions should be recorded as a narrative accompanying the recommendations.

Offshore fishing representatives, for example, strongly argued for MCZs to be located away from valuable fishing areas, in order to minimise negative impacts of MCZs on economic interests of offshore fleets (those using bottom-towed gears, in particular). Paradoxically, however, they objected to the recording of a joint assumption that MCZs would result in restrictions on bottom-towed gears:

Lieberknecht LM and Jones PJS (2016) From stormy seas to the doldrums: The challenges of navigating towards an ecologically coherent MPA network through England's Marine Conservation Zone process. Marine Policy 71, 275-284. http://dx.doi.org/10.1016/j.marpol.2016.05.023 Elsevier@2016. This manuscript version is made available under the CC-BY-NC-ND 4.0 license 
They feared that this would imply their support for the restriction. Thus, not only did uncertainty create conflicts, it also created complexity in conflicts.

Given the strength and complexity of the conflicts, reaching a 'consensus' within the group proved to be an unrealistic ambition. Some stakeholders fundamentally opposed marine protected areas, and would have preferred the MCZ process not to exist in the first place. In particular, offshore fishing representatives made it clear that they would continue to challenge both the MCZ process and specific site proposals, as well as any moves to restrict offshore fishing activities. The experience from the MCZ process highlights that fundamental conflicts cannot necessarily be planned or negotiated away through collaboration. Reaching a strategic objective (such as a representative MPA network and improved environmental status) may require top-down intervention, e.g. through the setting of minimum benchmarks such as the ENG, and through ultimate decisions being taken by government institutions (accepting that there may be losers as well as winners as a result).

Nevertheless, the collaborative work within regional projects proved successful. Regular RSG meetings provided a platform for conflicts to be brought into the open, and to be addressed with the support of professional facilitation. Despite the significant challenges within the discussions, stakeholders from across the spectrum of interest groups remained present throughout the planning discussions. In many instances, compromise solutions were reached through trade-offs and negotiations, which would not have been possible without cross-sector communication, and the development of a shared understanding of conflicts and synergies between different interests. All four RSGs were successful in jointly developing MCZ recommendations which largely met ENG guidelines, building significant social capital in the process.

In contrast, the current MCZ process has no alternative mechanism for resolving conflicts in any open or participative manner. Rather than incentivising collaboration and compromise across sectors, the current process effectively incentivises dissent, with campaigns and lobbying for sector-specific positions. Stakeholder interviews carried out a year after the end of the RSG meetings revealed an increase in levels of distrust between sectors, and increased tensions and conflicts between conservationists and offshore fishing industry representatives, in particular.

\section{The degree of integration}

The RSGs aimed to serve as platforms for integrating multi-sector interests through a process of tradeoffs and compromise. Thus, the regional projects provided a formal mechanism for multi-sector integration, despite the process having a 'single-sector objective' (biodiversity protection). However, the role and influence of the regional projects was limited, in both time and in remit. Most importantly, discussions about MCZ management were not within the formal remit of the RSGs.

Since the end of the regional projects, there has been no mechanism or incentive for further horizontal integration across multi-sector interests. On balance, therefore, the degree of horizontal integration within the on-going MCZ process is limited. It is possible that this will change in future, when management measures are defined by the regulatory authorities, but the details of the process through which this will happen remain uncertain at the time of writing.

Lieberknecht LM and Jones PJS (2016) From stormy seas to the doldrums: The challenges of navigating towards an ecologically coherent MPA network through England's Marine Conservation Zone process. Marine Policy 71, 275-284. http://dx.doi.org/10.1016/j.marpol.2016.05.023 Elsevier@2016. This manuscript version is made available under the CC-BY-NC-ND 4.0 license 
In terms of vertical integration across different levels of Government, local and regional government (parish councils, and county councils / unitary authorities) play no formal role in the MCZ process at all. The boundaries of administrative regions under local authority control in England generally do not extend beyond low water mark (except in some enclosed water bodies, such as inlets or estuaries). Like all public bodies, local authorities will have a duty to manage any activities under their control in such a way that the conservation objectives of MCZs are not compromised. However, the Marine Act gives them no power over decisions on where to designate sites, or on defining their conservation objectives.

The regional projects provided a degree of vertical integration within the process while they operated. Four south-west county councils were represented on the Finding Sanctuary's management board. Local authorities also form part of the IFCAs, who will be responsible for implementing management measures in inshore MCZs.

\section{Participation, transparency and accountability}

A minimum level of stakeholder participation in the on-going process is guaranteed, as Defra has a legal obligation to conduct a public consultation on any site intended for designation, and regulatory authorities must do the same for any byelaw they wish to impose in order to protect a site (unless there are imminent threats to conservation objectives, in which case temporary emergency byelaws may be imposed subject to subsequent consultation on permanent byelaws). There is no legal requirement for any level of participation beyond consultation, however, such as collaborative planning or co-decision making. Thus, the regional projects went beyond the formal requirements of the process, enabling all affected groups to influence planning from the start, and incentivising crosssector collaboration (horizontal integration).

Several of Finding Sanctuary's RSG members struggled with the responsibility of representing their constituency, especially those with limited resource to invest in the process, and those whose constituencies are large, variable, and diffuse (i.e. lacking representative bodies). Regional project staff provided support (e.g. providing maps and information to share with constituents, organising sector-specific events to inform and gather feedback), but participation was nevertheless challenging and time-consuming for stakeholders. The fact that they continued to participate constructively in regular meetings reflects that they valued their role within the process. In their final meeting, Finding Sanctuary's RSG made a joint statement to express their wish for a continued role in the MCZ process, and for their remit to extend to the planning of management measures [3].

Following their final meetings in July 2011, however, the RSGs were disbanded. Opportunities for formal participation abruptly went from collaborative to non-existent, except for the opportunity to comment on tranche 1 proposals during the public consultation period from December 2012 to March 2013. The $2012 / 2013$ consultation documents made it clear that are no plans for increased participation (e.g. multi-sectoral collaboration or co-decision making) within the MCZ process in the foreseeable future [18].

The change in approach effectively incentivised campaigning and lobbying for sector-specific positions, perpetuating and intensifying conflicts rather than addressing or resolving them. Open lobbying effort

Lieberknecht LM and Jones PJS (2016) From stormy seas to the doldrums: The challenges of navigating towards an ecologically coherent MPA network through England's Marine Conservation Zone process. Marine Policy 71, 275-284. http://dx.doi.org/10.1016/j.marpol.2016.05.023 Elsevier@2016. This manuscript version is made available under the CC-BY-NC-ND 4.0 license 
has been significant, in particular, from bodies representing offshore fishing interests, and from conservation NGOs. It is likely that other sectors have also exerted pressure on officials and decisionmakers. National industry bodies (e.g. representing ports, shipping, aggregates, and energy developers) have access to officials in a range of marine and maritime forums. However, there is a lack of transparency in these interactions - from the outside, it is often not clear who has had opportunities to interact with who, when, and what the content of discussions has been. This makes it impossible to analyse these interactions, and any conflicts emerging from them, to the same level of detail as the interactions and conflicts that emerged from Finding Sanctuary's stakeholder discussions. The 2012 interviews with former RSG members indicated a marked decline in trust and communication between sectors since the end of the RSG meetings, with interviewees from across multiple sectors believing lobbying was happening 'behind closed doors'. Interviewees from different sectors usually felt that sectors with opposing viewpoints were wielding more influence than their own.

The interviews also revealed a lack of trust in Defra and the SNCBs, compounded by the loss of transparency from the process. The regional projects had published information about their developing MCZ recommendations from the beginning, including maps of sites under discussion and reports of all stakeholder meetings. Many stakeholders perceived a sudden 'radio silence' immediately following what had been an intense, demanding, and information-rich process. It was not clear to them what was happening during the 14-month interlude between the submission of the RSGs' MCZ recommendations, and the start of the public consultation in December 2012. Over that period, no substantive information was shared by Defra or the SNCBs on which sites might be included in the first tranche, and what specific criteria their selection would be based on. Apart from leading to disillusionment and disengagement from the process, this allowed rumours to flourish, generating a climate of distrust.

In terms of accountability, the Marine Act ultimately makes the environment minister accountable for the successful implementation of MCZs - he or she has to report to Parliament on their conservation status every six years. At a more detailed level within the on-going process, staff turnover within Defra and the SNCBs has made it difficult to hold specific individuals accountable for the successful completion of specific process elements and milestones.

\section{Equity and justice}

Finding Sanctuary carried out an extensive stakeholder analysis to ensure all interests were appropriately represented and balanced. Nevertheless, RSG membership was a frequent topic of intense discussion, as perceptions of what constituted 'balanced representation' differed significantly between different participants. For example, fishermen constituted the single largest sectoral fraction of the RSG, but felt under-represented: Many fishermen thought that they deserved a stronger influence over outcomes than other sectors, as they viewed livelihoods within their sector being at stake, whilst other participants had less to lose. However, many other maritime industries regarded MCZs as a potentially significant risk to their sector, and therefore felt equally deserving of influence. Environmental representatives strongly opposed the fishermens' perspective, taking the view that every person ultimately has a strong stake in a healthy marine ecosystem and environmental sustainability.

Lieberknecht LM and Jones PJS (2016) From stormy seas to the doldrums: The challenges of navigating towards an ecologically coherent MPA network through England's Marine Conservation Zone process. Marine Policy 71, 275-284. http://dx.doi.org/10.1016/j.marpol.2016.05.023 Elsevier@2016. This manuscript version is made available under the CC-BY-NC-ND 4.0 license 
Despite these difficulties, the RSGs provided a formal mechanism for achieving full representation of all stakeholder interests within the MCZ process, with dedicated efforts to make information accessible, and provide added support to stakeholder groups with limited means. At the time of writing, there no longer are any equivalent mechanisms in place, and the lack of transparency discussed above makes it difficult to assess the levels of influence that different interests wield in reality.

The summer 2012 interviews revealed that following the final RSG meeting, levels of access to the national MCZ process had varied considerably between sectors. Defra and the SNCBs continued to engage with some stakeholder representatives on an ad-hoc basis, e.g. through discussing progress on MCZs at meetings of existing national marine forums (including industry forums). Stakeholder representation on such forums tends to be limited to national-level industry bodies and NGOs, arguably giving these bodies privileged access to officials and information within the MCZ process, compared to other stakeholders who had been represented in RSGs.

At the time of writing, arguably the MCZ process has produced no winners (except for the environmental consultancies contracted to support evidence gathering and reviews). The process has spent effort, stakeholder time and goodwill (social capital), as well as public money, but with no protection measures in place on the ground, no environmental benefits have yet been realised. It is too early to say whether the outcomes of the MCZ process (including management measures within MCZs) will be fair and just.

There is a legal mechanism that can be used for challenging public decision-making processes in the UK, which could be applied to the MCZ process in future: Judicial Review, which focuses on the process by which a decision was made, not the decision itself. Grounds for Judicial Review include the proportionality, fairness, and legality of a process. Bringing forward a challenge, however, requires access to sufficient funds and legal expertise, so in practice, it is not equally accessible to all.

\section{Uncertainty}

Like any environmental planning process, the MCZ process operates within a context of scientific uncertainty, e.g. gaps in spatial datasets on species and habitat distributions. This was acknowledged in policy guidance from the start of the process. One of Defra's seven principles underpinning the development of the MPA network was that 'Network design should be based on the best information currently available. Lack of full scientific certainty should not be a reason for postponing proportionate decisions on site selection.' [1].

The ENG was anchored in this principle, and the regional projects proceeded based on best available information, including modelled data for broad-scale seafloor habitats, which were used as a surrogate for detailed biodiversity information. However, through 2011 a shift in policy on scientific evidence became apparent. In May 2011, the SNCBs published a guidance document which stated that whilst site 'identification' (the work done by the RSGs) could proceed based on 'best available' evidence, modelled data would not suffice for underpinning site designation, and detailed evidence would be needed to justify the implementation of management measures following designation [19]. This shift became further evident when the November 2011 written Ministerial Statement emphasised

Lieberknecht LM and Jones PJS (2016) From stormy seas to the doldrums: The challenges of navigating towards an ecologically coherent MPA network through England's Marine Conservation Zone process. Marine Policy 71, 275-284. http://dx.doi.org/10.1016/j.marpol.2016.05.023 Elsevier@2016. This manuscript version is made available under the CC-BY-NC-ND 4.0 license 
the need for an 'adequately robust evidence base', and cited lack of sufficient evidence as a key reason for delaying site designation. Arguably, this shift is incompatible with the precautionary principle embedded in the EU Treaty (see [13]).

The new approach effectively places evidence 'hurdles' of increasing height in the way of achieving a representative and well-managed MPA network. These hurdles are magnified and multiplied by the fact that MCZ conservation objectives are not being written for integral sites or for the network, but for individual features, necessitating detailed information on the distribution and condition of individual species and habitats in each site [2].

There is a second type of uncertainty of key importance in the MCZ process - uncertainty about future MCZ management. This is generated through the design of the process, which separates the planning of MCZ locations and boundaries from planning MCZ management. They are designed as separate tasks, carried out in sequence. As a consequence, RSGs had to develop MCZ recommendations without knowing how MCZs would impact them in future (one interviewee described this as 'flying blind'). RSG members overwhelmingly felt that their task was not complete and meaningful without addressing site management, but their remit was restricted to site location, boundaries, and conservation objectives.

In addition to driving conflicts, this uncertainty has, to date, prevented the achievement of 'well understood' sites (people do not understand what MCZs will mean in reality). It has lowered support for MCZs (people fear 'worst-case scenarios' for their sector). It has also caused significant stakeholder frustration with the MCZ process, because despite being raised repeatedly and emphatically as a key concern, there has as yet never been any clear push from Defra or the SNCBs to resolve the issue (e.g. through unambiguous guidance on future MCZ management, or through expansion of the RSG remit and lifespan to cover management planning).

Perhaps most significantly, the MCZ Impact Assessment [10] had to be based on 'illustrative management scenarios', arguably rendering the cost figures it contained highly uncertain. Nevertheless, 'unacceptable' cost was a key reason for keeping recommended MCZs out of the first tranche [9]. The weight given to uncertain cost figures stands in marked contrast to the lack of tolerance for uncertainty in the scientific evidence underpinning site recommendations.

\section{Conclusions}

The most salient aspect of the MCZ process to date is the marked shift between planning approaches. The initial approach, embodied by the regional projects, was systematic, broad-scale, and focussed on building a representative MPA network, based on best available information. It strived for transparency, and combined strong participative, bottom-up elements (cross-sector stakeholder collaboration) with strong top-down elements (guidelines such as the ENG, and decision-making power retained by Government). The process subsequently shifted to an almost fully top-down approach, with no collaborative elements, and a lack of transparency. The focus was re-scaled from the network level towards protecting specific features in individual sites, demanding detailed levels of evidence, by far exceeding the best information available at present, especially for offshore sites.

Lieberknecht LM and Jones PJS (2016) From stormy seas to the doldrums: The challenges of navigating towards an ecologically coherent MPA network through England's Marine Conservation Zone process. Marine Policy 71, 275-284. http://dx.doi.org/10.1016/j.marpol.2016.05.023 Elsevier@2016. This manuscript version is made available under the CC-BY-NC-ND 4.0 license 
Despite major challenges (e.g. those posed by management uncertainty), the initial approach made significant progress towards developing a coherent network of MCZs. The RSGs navigated through the stormy waters of open conflict and negotiation, generating $127 \mathrm{MCZ}$ recommendations in line with the ENG and Defra's network principles. The subsequent shift in planning approach and in Government policy moved the process out of these stormy waters into the doldrums of multiple evidence reviews, the effective deconstruction of the network into a small number of its constituent parts, and significant delays in the designation timetable.

Marking perhaps the most significant shift in the process, in March 2013, the responsible minister stated that the ENG would no longer be considered a benchmark for assessing the ecological coherence of the network, and that Government would instead use the (considerably weaker) OSPAR criteria [20] in future ${ }^{\mathrm{xvi}}$. Given that the ENG operationalised policy principles that were framed by Defra at the start of the process [1], and that they were the only practical network design guidelines provided to the RSGs throughout their operation, this constitutes a remarkable shift in policy, and the goal of the MCZ process, effectively undermining the work carried out by the RSGs.

In conclusion, the MCZ process has shifted significantly from the course it originally embarked upon, and is now heading towards an uncertain future. With NGO-led campaigns to implement all 127 recommended MCZs, on-going industry lobbying, the potential for legal challenges both from industry and from conservation NGOs, and management measures yet to be defined, the only certainty in the current MCZ process is that more stormy waters lie ahead. The future course and ultimate destination will be strongly determined by the prevailing winds of political will.

\section{Acknowledgements}

This research was funded by the European Commission under the 'Monitoring and Evaluation of Spatially Managed Marine Areas' (MESMA) project (www.mesma.org), as part of the 7th Framework Programme. Thanks are due to Finding Sanctuary's stakeholders and staff for permitting the observation of their meetings, and to the 23 former RSG members who agreed to be interviewed in summer 2012. Thanks are also due to Dr Wanfei Qiu for discussions about this case study and feedback on this manuscript.

\section{References}

[1] Defra. Guidance on selection and designation of Marine Conservation Zones (Note 1). London: Department for Environment, Food and Rural Affairs; 2010.

http://webarchive.nationalarchives.gov.uk/20130402151656/http://archive.defra.gov.uk/environm ent/biodiversity/marine/documents/guidance-note1.pdf (accessed 30/10/2013)

[2] Lieberknecht LM, Qiu W, Jones PJS. Celtic Sea Case Study Governance Analysis - Finding Sanctuary and England's Marine Conservation Zone process. University College London; 2013. http://www.homepages.ucl.ac.uk/ ucfwpej/pdf/FindingSanctuaryGovernanceAnalysisFull.pdf (accessed 30/10/2013)

Lieberknecht LM and Jones PJS (2016) From stormy seas to the doldrums: The challenges of navigating towards an ecologically coherent MPA network through England's Marine Conservation Zone process. Marine Policy 71, 275-284. http://dx.doi.org/10.1016/j.marpol.2016.05.023 Elsevier@2016. This manuscript version is made available under the CC-BY-NC-ND 4.0 license 
[3] Lieberknecht LM, Hooper TEJ, Mullier TM, Murphy A, Neilly M, Carr H, Haines R, Lewin S, Hughes $E$. Finding Sanctuary final report and recommendations. A report submitted by the Finding Sanctuary stakeholder project to Defra, the Joint Nature Conservation Committee, and Natural England. 2011.

http://jncc.defra.gov.uk/PDF/120718_FindingSanctuary_FinalReport_14Sep2011.pdf (accessed 30/10/2013)

[4] Jones PJS, Lieberknecht LM, Qiu W (2016) Marine Spatial Planning in reality: introduction to case studies and discussion of findings. Marine Policy 71, 256-264, Open Access doi:10.1016/j.marpol.2016.04.026.

[5] De Santo EM, Jones PJS. Offshore marine conservation policies in the North East Atlantic: Emerging tensions and opportunities. Marine Policy 2007; 31(3): 336-347. doi:10.1016/j.marpol.2010.09.004 - Copy of paper

[6] JNCC, Natural England. Marine Conservation Zone Project - Ecological Network Guidance. Peterborough: 2010.

http://jncc.defra.gov.uk/pdf/100705_ENG_v10.pdf (accessed 30/10/2013)

[7] MCZ Science Advisory Panel. Science Advisory Panel Assessment of the Marine Conservation Zone Regional projects Final Recommendations. 2011.

https://www.gov.uk/government/publications/science-advisory-panel-assessment-of-the-marineconservation-zone-regional-project-final-recommendations (accessed 30/10/2013)

[8] JNCC, Natural England. Marine Conservation Zone Project - JNCC and Natural England's advice to Defra on recommended Marine Conservation Zones. Peterborough: 2012. http://jncc.defra.gov.uk/PDF/MCZProjectSNCBAdviceBookmarked.pdf (accessed 30/10/2013)

[9] Defra. Steps for assessing Marine Conservation Zone proposals. London: Department for Environment, Food and Rural Affairs; 2013.

https://www.gov.uk/government/uploads/system/uploads/attachment_data/file/181830/pb13896mcz-selection-process.pdf.pdf (accessed 30/10/2013)

[10] Defra. Impact Assessment. Designation of Marine Conservation Zones in English Inshore waters and English and Welsh Offshore waters. London: Department for Environment, Food and Rural Affairs; 2012.

https://www.gov.uk/government/uploads/system/uploads/attachment_data/file/82721/mczdesignate-ia-20121213.pdf (accessed 30/10/2013)

[11] Wilson LC, Elliott M, Cutts ND, Mander L, Mendo V, Perez Dominguez R, Phelps A. Coastal and offshore wind energy generation: Is it environmentally benign? Energies 2010; 3(7): 1383-1422.

[12] Lee J, South $A B$, Jennings $S$. Developing reliable, repeatable, and accessible methods to provide high-resolution estimates of fishing-effort distributions from vessel monitoring system (VMS) data. ICES Journal of Marine Science 2010; 67(6): 1260- 1271.

Lieberknecht LM and Jones PJS (2016) From stormy seas to the doldrums: The challenges of navigating towards an ecologically coherent MPA network through England's Marine Conservation Zone process. Marine Policy 71, 275-284. http://dx.doi.org/10.1016/j.marpol.2016.05.023 Elsevier@2016. This manuscript version is made available under the CC-BY-NC-ND 4.0 license 
[13] Qiu WF, Jones PJS. The emerging policy landscape for marine spatial planning in Europe. Marine Policy 2013; 39: 182-190. Open Access- doi:10.1016/j.marpol.2012.10.010

[14] Rees SE, Rodwell LD, Searle S, Bell A. Identifying the issues and options for managing the social impacts of Marine Protected Areas on a small fishing community. Fisheries Research 2013; 146: 5158.

[15] Ehler C, Douvere F. Marine Spatial Planning: a step-by-step approach toward ecosystem-based management. Intergovernmental Oceanographic Commission and Man and the Biosphere

Programme. IOC Manual and Guides No. 53, ICAM Dossier No. 6. Paris: UNESCO; 2009.

[16] Ehler C, Douvere F. Visions for a Sea Change. Report of the First International Workshop on Marine Spatial Planning. Intergovernmental Oceanographic Commission and Man and the Biosphere Programme. IOC Manual and Guides 46, ICAM Dossier No. 3. Paris: UNESCO; 2007.

[17] Leslie HM, McLeod KL. Confronting the challenges of implementing marine ecosystem-based management. Frontiers in Ecology and the Environment 2007; 5(10): 540-548.

[18] Defra. Marine Conservation Zones: Consultation on proposals for designation in 2013. London: Department for Environment, Food and Rural Affairs; 2012. https://www.gov.uk/government/uploads/system/uploads/attachment_data/file/82730/mczcondoc-121213.pdf (accessed 30/10/2013)

[19] JNCC, Natural England. Levels of evidence required for the identification, designaton and management of Marine Conservation Zones. Peterborough: 2011. http://jncc.defra.gov.uk/pdf/110506_LevelsOfEvidenceForMCZs.pdf (accessed 30/10/2013)

[20] OSPAR. Guidance on developing an ecologically coherent network of OSPAR marine protected areas, Reference number 2006-3. OSPAR Commission; 2006.

\section{Endnotes}

' Marine and Coastal Access Act 2009

http://www.legislation.gov.uk/ukpga/2009/23/contents (accessed 30/10/2013)

ii Section 116 of the Marine and Coastal Access Act 2009: "Marine Conservation Zones":

“ (1) The appropriate authority may by order designate any area falling within subsection (2) as a marine conservation zone (an "MCZ"). [...]

(2) An area falls within this subsection if-

(a) it is an area of the sea within the seaward limits of the territorial sea adjacent to the United Kingdom;

(b) it is an area of the sea within the limits of the exclusive economic zone;

(c) it is an area of the sea bed or subsoil within the limits of the UK sector of the continental shelf (so far as not falling within an area mentioned in paragraph (b)).

(3) But an area does not fall within subsection (2) if it is in-

(a) the Scottish inshore region, or

(b) the Northern Ireland inshore region. [...]

(5) For the purposes of this Chapter the appropriate authority is-

Lieberknecht LM and Jones PJS (2016) From stormy seas to the doldrums: The challenges of navigating towards an ecologically coherent MPA network through England's Marine Conservation Zone process. Marine Policy 71, 275-284. http://dx.doi.org/10.1016/j.marpol.2016.05.023 Elsevier@2016. This manuscript version is made available under the CC-BY-NC-ND 4.0 license 
(a) in relation to an area in Wales, the Welsh Ministers;

(b) in relation to an area in the Scottish offshore region, the Scottish Ministers;

(c) in any other case, the Secretary of State. [...]"

iii Council Directive 92/43/EEC of 21 May 1992 on the conservation of natural habitats and of wild fauna and flora

http://eur-lex.europa.eu/LexUriServ/LexUriServ.do?uri=CELEX:01992L0043-20070101:EN:NOT (accessed $30 / 10 / 2013$ )

iv Directive 2009/147/EC of the European Parliament and of the Council of 30 November 2009 on the conservation of wild birds (amended from Directive 79/409/EEC)

http://eur-lex.europa.eu/LexUriServ/LexUriServ.do?uri=OJ:L:2010:020:0007:0025:EN:PDF (accessed 30/10/2013)

"Section 123 of the Marine and Coastal Access Act 2009: "Creation of network of conservation sites":

“(1) In order to contribute to the achievement of the objective in subsection (2), the appropriate authority must designate MCZs under section 116.

(2) The objective is that the MCZs designated by the appropriate authority, taken together with any other MCZs designated under section 116 and any relevant conservation sites in the UK marine area, form a network which satisfies the conditions in subsection (3).

(3) The conditions are-

(a) that the network contributes to the conservation or improvement of the marine environment in the UK marine area;

(b) that the features which are protected by the sites comprised in the network represent the range of features present in the UK marine area;

(c) that the designation of sites comprised in the network reflects the fact that the conservation of a feature may require the designation of more than one site. [...]"

vi Section 117 of the Marine and Coastal Access Act 2009: "Grounds for designation of MCZs":

“(1) The appropriate authority may make an order under section 116 if it thinks that it is desirable to do so for the purpose of conserving-

(a) marine flora or fauna;

(b) marine habitats or types of marine habitat;

(c) features of geological or geomorphological interest. [...]"

vii Directive 2008/56/EC of the European Parliament and of the Council of 17 June 2008 establishing a framework for community action in the field of marine environmental policy (Marine Strategy Framework Directive), Article 13 (4):

“4. Programmes of measures established pursuant to this Article shall include spatial protection measures, contributing to coherent and representative networks of marine protected areas, adequately covering the diversity of the constituent ecosystems, such as special areas of conservation pursuant to the Habitats Directive, special protection areas pursuant to the Birds Directive, and marine protected areas as agreed by the Community or Member States concerned in the framework of international or regional agreements to which they are parties."

http://eur-lex.europa.eu/LexUriServ/LexUriServ.do?uri=CELEX:32008L0056:EN:NOT (accessed 30/10/2013)

viii Written Ministerial Statement by Huw Irranca-Davies - The creation of a network of Marine Protected Areas, 2010.

http://webarchive.nationalarchives.gov.uk/20100401103043/http:/www.defra.gov.uk/corporate/about/who/ ministers/statements/hid100311.htm (accessed 30/10/2013)

ix The SAP's Terms of Reference defined the role of the SAP as follows: "To provide the independent scientific knowledge, advice and judgement necessary to assist the regional MCZ projects in identifying Marine

Lieberknecht LM and Jones PJS (2016) From stormy seas to the doldrums: The challenges of navigating towards an ecologically coherent MPA network through England's Marine Conservation Zone process. Marine Policy 71, 275-284. http://dx.doi.org/10.1016/j.marpol.2016.05.023 Elsevier@2016. This manuscript version is made available under the CC-BY-NC-ND 4.0 license 
Conservation Zones (MCZs) and the Secretary of State (SoS) in designating Marine Conservation Zones as a contribution to an ecologically coherent network of MPAs. [...] Specifically the SAP will: provide expert scientific advice and address scientific questions raised by the regional MCZ projects and their steering groups; assist the regional projects in working to consistent standards and to ensure network proposals are consistent with network design guidance; review any alternative MCZ proposals submitted by the regional projects against the criteria within the network design guidance and re-send to panel members; Provide quarterly reports on its work to the MCZ Project Board; and advise NE and JNCC, and the SoS, as to whether MCZ proposals meet the criteria in the network design guidance and in combination with other MPAs contribute to the delivery of an ecologically coherent network."

http://webarchive.nationalarchives.gov.uk/20130402151656/http://archive.defra.gov.uk/environment/marin e/documents/protected/mpasap-tor.pdf (accessed 30/10/2013)

x Written Ministerial Statement on Marine Conservation Zones by Richard Benyon, November $15^{\text {th }}, 2011$ http://www.defra.gov.uk/news/2011/11/15/wms-marine-conservation-zones/ (accessed 30/10/2013)

${ }^{x i}$ Directive 2009/28/EC of the European Parliament and of the Council of 23 April 2009 on the promotion of the use of energy from renewable sources http://eur-lex.europa.eu/legal-content/EN/ALL/?uri=CELEX:32009L0028 (accessed 30/10/2013)

xii Wave Hub http://www.wavehub.co.uk/about/ (accessed 30/10/2013)

xiii Marine Management Organisation Public Register, Falmouth Harbour construction works, capital dredge and maërl mitigation scheme

http://webarchive.nationalarchives.gov.uk/20140108121958/http://www.marinemanagement.org.uk/licensin g/public_register/cases/falmouth.htm (accessed 30/10/2013)

${ }^{\text {xiv }}$ e.g. The Guardian (http://www.guardian.co.uk/environment/2012/feb/04/falmouth-dredging-environmenttourism-row, accessed 30/10/2013), local press

(http://www.falmouthpacket.co.uk/in_port/9603090.Dredging_trial_plan_revealed/, accessed 30/10/2013) and the BBC (http://www.bbc.co.uk/news/uk-england-cornwall-16776479, accessed 30/10/2013)

${ }^{x v}$ e.g. The Daily Telegraph http://www.telegraph.co.uk/earth/wildlife/8615766/Sailors-vs-seahorses-thebattle-of-Studland-Bay.html (accessed 30/10/2013) and the Daily Mail

http://www.dailymail.co.uk/news/article-2365731/Fight-save-seahorses-Studland-Bay-Wealthy-yachties-wipeBritains-largest-colony-dropping-anchor-habitat.html (accessed 30/10/2013)

xvi Hansard, 14 ${ }^{\text {th }}$ March 2013, Column 311W, response by Richard Benyon to a question from Dr Offord http://www.publications.parliament.uk/pa/cm201213/cmhansrd/cm130314/text/130314w0002.htm (accessed 30/10/2013)

Lieberknecht LM and Jones PJS (2016) From stormy seas to the doldrums: The challenges of navigating towards an ecologically coherent MPA network through England's Marine Conservation Zone process. Marine Policy 71, 275-284. http://dx.doi.org/10.1016/j.marpol.2016.05.023 Elsevier@2016. This manuscript version is made available under the CC-BY-NC-ND 4.0 license 